\title{
Optical Characterization of Different Thin Film Module Technologies
}

\author{
R. Ebner, B. Kubicek, G. Újvári, S. Novalin, M. Rennhofer, and M. Halwachs \\ Photovoltaic Systems, Energy Department, Austrian Institute of Technology (AIT), Giefinggasse 2, 1210 Vienna, Austria \\ Correspondence should be addressed to R. Ebner; rita.ebner@ait.ac.at
}

Received 26 November 2014; Revised 23 March 2015; Accepted 23 March 2015

Academic Editor: Aldo Di Di Carlo

Copyright (C) 2015 R. Ebner et al. This is an open access article distributed under the Creative Commons Attribution License, which permits unrestricted use, distribution, and reproduction in any medium, provided the original work is properly cited.

For a complete quality control of different thin film module technologies (a-Si, CdTe, and CIS) a combination of fast and nondestructive methods was investigated. Camera-based measurements, such as electroluminescence (EL), photoluminescence (PL), and infrared (IR) technologies, offer excellent possibilities for determining production failures or defects in solar modules which cannot be detected by means of standard power measurements. These types of optical measurement provide high resolution images with a two-dimensional distribution of the characteristic features of PV modules. This paper focuses on quality control and characterization using EL, PL, and IR imaging with conventional cameras and an alternative excitation source for the PL-setup.

\section{Introduction}

EL, PL, and IR imaging are nondestructive measurement techniques. These types of optical measurement provide fast, real-time, and high resolution images with a two-dimensional distribution of the characteristic features of PV modules. These technologies are applied effectively in quality control and development support and are important characterization tools in industry and research. In previous works, a combination of EL and IR measurements was proposed in order to quickly detect the most common defects in a PV module with high accuracy [1-3]. In this work a combination of EL, PL, and IR characterization tools is presented with the aim to increase the number of detectable defects and to determine their origin.

\section{Theoretical Background}

2.1. IR-Thermography. By means of IR measurements the thermal behavior of cells in a module and a number of defects (e.g., short circuits in solar cells, shunts, inactive cell parts, moisture, and defective bypass diodes) can be determined $[4,5]$. IR measurements can be taken by using an external current or by applying light as heat source. Illuminated thermography imaging makes a comparison of modules operated under different conditions, such as short circuit $\left(I_{\mathrm{sc}}\right)$, open circuit $\left(U_{\mathrm{oc}}\right)$, and maximum power point $\left(P_{m}\right)$, possible. Several defects can be distinguished by varying the electrical load corresponding to certain states of the current-voltage characteristics [1].

In order to avoid thermal damaging in thin film modules, it has to be observed that the short circuit current of the module is not exceeded. For low voltages, below the threshold voltage of the diode, the current flows through the parallel resistance $\left(R_{p}\right)$ and the series resistance $\left(R_{s}\right)$. As $R_{s}<R_{p}$, the heating is mainly due to shunted areas. For voltages over the threshold, a large amount of the current flows through the diode itself and heats up the diode and the series resistance [6].

During measurements in the dark, no light is applied to the module but an external current (less than or equal to the short circuit current $\left.\left(I_{\mathrm{sc}}\right)\right)$ is supplied in forward direction [7]. In a previous work it was shown that dark thermography compared to illuminated thermography is a better tool for thin film modules [3]. Dark thermography images of thin film modules offer more detail and a better defect resolution compared to illuminated thermography images.

By means of an appropriate IR-camera, the temperature distribution can be identified and compared to EL and PL 
measurements. Thermography imaging at AIT was performed by means of a portable, uncooled IR-camera. The wavelength sensitivity of the used IR-detector is between $7.5 \mu \mathrm{m}$ and $15 \mu \mathrm{m}$. As the front plate of all measured PV modules consists of a glass plate with a thickness of 3-4 mm and thus is only transparent for detectors with a wavelength of 3 to $5 \mu \mathrm{m}$, only the temperature of the glass surface can be measured and not the radiation coming directly from the solar cells.

2.2. Dark Lock-In Thermography (DLIT). Dark lock-in thermography is a further nondestructive test method [8]. For DLIT, pulsed current is applied to the solar cell without illumination. Then, only the dark current flows within the cell. At shunt sites, an increased current causes heating of the solar cell which can be easily detected by LIT. The variations in temperature are in the area of one-tenth degree. The Fourier analysis of the local variations in temperature can be characterized as sinus wave with amplitude and phase. The ground frequency amplitude image gives information about the intensity of the heating sources in a module.

The dark lock-in thermography was mainly developed for the detection of shunts [9]. Noises, resolution, and contrast of DLIT analysis depend on the used excitation frequency as well as the recording time. By means of a cooled microbolometer based IR-camera and a power supply unit, a DLIT-System was built up. DLIT can be used for detailed failure analysis.

2.3. Electroluminescence (EL). EL measurements take advantage of the radiative interband recombination of excited charge carriers in solar cells. For EL investigations the module is operated as a light emitting diode. The emitted radiation due to recombination effects can be detected with a sensitive $\mathrm{Si}$-CCD-camera. The wavelength window of the Si-CCDcamera is 300 to $1000 \mathrm{~nm}$.

The solar cells are supplied with a defined external excitation current (current applied $\leq$ short circuit current $\left(I_{\mathrm{sc}}\right)$ of the cell or module) while the camera takes an image of the emitted photons. Damaged areas of a solar module appear dark or radiate less than areas without defects. EL has proven to be a useful tool for investigating electrical inhomogeneities caused by intrinsic defects (e.g., grain boundaries, dislocations, shunts, or other process failures) and extrinsic defects (e.g., cell cracks, TCO corrosion, or interrupted contacts) [10-15]. The high resolution of the EL-images enables resolving some defects more precisely than in IR-images.

To determine the influence of defects (e.g., shunts), the EL-behavior of modules was investigated with different current densities [16]. When applying a low current density ( $\sim 1 / 10$ of the $I_{\mathrm{sc}}$ of the cell or module) the conductivity of shunts is very high. When applying higher current densities $\left(\sim I_{\text {sc }}\right.$ of the cell or module), the conductivity of the pnjunction increases compared to the shunt conductivity, and shunts are less influential on the EL intensity distribution. Thus, with low current densities, the material properties and, with high current densities, the properties of the electrical contacts can be investigated.

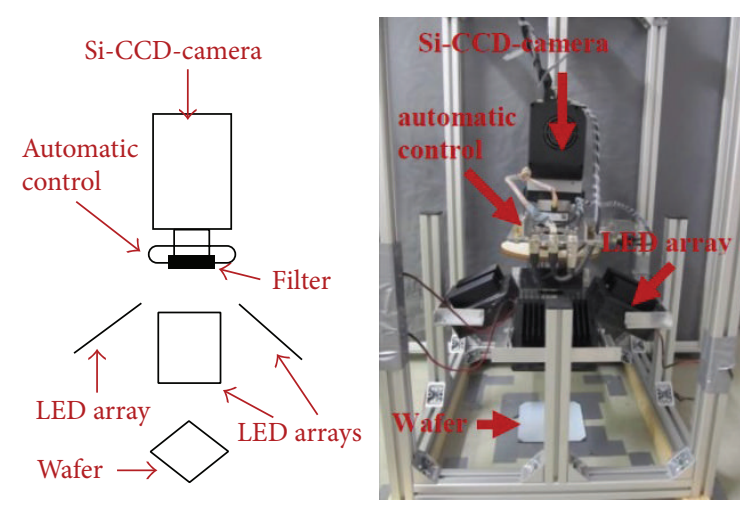

FIGURE 1: PL-setup.

2.4. Photoluminescence (PL). Photoluminescence (PL) imaging is, in contrast to EL imaging, a contactless and nondestructive measurement technique [17]. As no electric contacts are required, PL can be applied to solar cells before and after each processing stage.

The combination of PL imaging with EL imaging of finished cells gives further information about cell performance losses (e.g., resistance losses).

In PL imaging systems commonly high power lasers are used to generate excess charge carriers, and an InGaAs-CCDcamera works as detector. But as this equipment has limited resolution capacity, alternative equipment was searched for $[18,19]$. Light emitting diode (LED) arrays turned out to be a very cost efficient alternative excitation source and further, a cooled Si-CCD-camera was used instead of an InGaAs camera.

The PL system built up at AIT consists of a sensitive Si-CCD-camera (300 to $1000 \mathrm{~nm}$ wavelength window) and different innovative IR-LED arrays with a peak wavelength between $534 \mathrm{~nm}$ and $850 \mathrm{~nm}$ (see Figure 1). Each LED spectrum was chosen to have a negligible overlap with the luminescence spectrum (950-1200 nm). In our setup the camera is placed on the same side as the LED arrays. This requires good filtering as a large portion of the excitation light is reflected on the wafer and strikes the camera. This is performed by a twostep filter, of which one is a custom-made anti-reflex-coated GaAs wafer, which is transparent in the range of the emitted PL photons. The second filter is a normal LP optical filter in front of the camera. The PL-setup as well as the EL-setup at AIT consists of an automatic control system, featuring a custom-made autofocus system. The problem is that the focus for visible and IR is different, and PL exposure times can be larger than 30 seconds. As manual focusing would be resource consuming, a computer-controlled system was created for this task. The measure for the sharpness is the average deviation of pixel brightness, and the approach occurs by a trisection algorithm, similar to normal binary dissection methods.

The PL-setup as well as the EL-setup at AIT consists of an automatic control system, featuring a custom-made autofocus system.

Depending upon the materials and the technology used, solar cells are better or worse at converting the different 


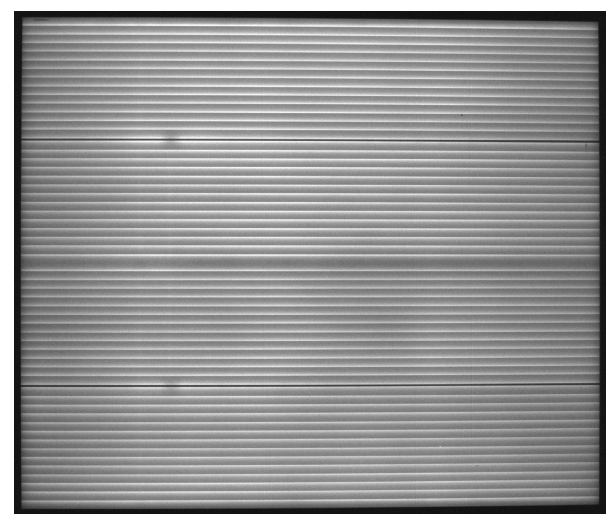

FIgURE 2: EL-image, a-Si-module (before aging).

color bands of sunlight into electricity. The spectral sensitivity describes the wavelength range in which a cell works most efficiently and influences the efficiency under different irradiance conditions. While crystalline solar cells are particularly sensitive to long wavelength solar radiation, thin film cells utilize the visible light better. Amorphous silicon cells can absorb short wavelength light optimally. In contrast, CdTe and CIS are better at absorbing medium wavelength light. Because of the different sensitivity of thin film cells, for PL measurements of these technologies, also different LEDs have to be used. For a-Si-modules LED arrays with a peak wavelength of $550 \mathrm{~nm}$, for CdTe-modules arrays with a peak wavelength of $680 \mathrm{~nm}$, and for CIS/CIGS arrays with a peak wavelength of $850 \mathrm{~nm}$ are used. PL measurements of CIS, $\mathrm{CdTe}$, and a-Si-modules were performed and compared with EL-images.

\section{Experiments}

\subsection{Characterization of a-Si-Module}

3.1.1. Characterization of an a-Si-Module before and after Aging Process. An a-Si-module was characterized, respectively, before and after performing some aging tests (preconditioning via light soaking, applying a reverse current). EL, IR, and performance measurements were executed and the results were compared. In the EL-image of the a-Si-module before aging (see Figure 2) there are no significant defects visible.

In the IR-image (see Figure 3 ) of the same module there are also hardly any defects identifiable. Only the metallic junction box was viewable as cooler area in the IR-image.

The EL-image of the a-Si-module after aging (Figure 4) mainly shows punctual shunts inside a cell or between the metal layers of two adjacent cells. In the cell area the punctual shunts appear as black points and between two cells, where the current flows through the shunt to the Si-layer of the next cell, bright points appear in the EL-image. The bright points are caused by increased recombination of electron-hole pairs and/or increased thermal radiation in the surroundings of the shunt area [20].

The dark thermography image of the a-Si-module (see Figure 5) almost shows the same defects compared to the
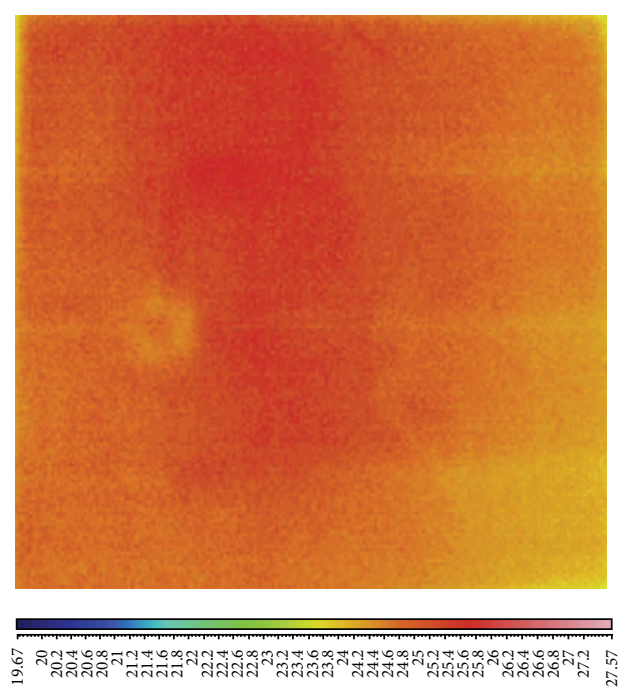

$\left({ }^{\circ} \mathrm{C}\right)$

FIGURE 3: Dark IR-image, a-Si-module (before aging).

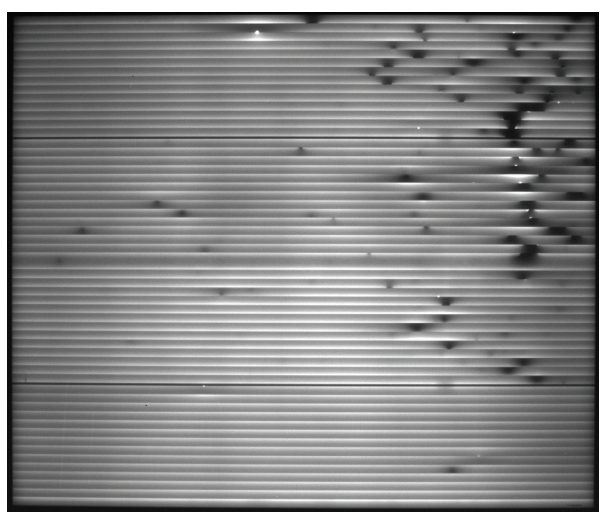

FIgURE 4: EL-image, a-Si-module (after aging).

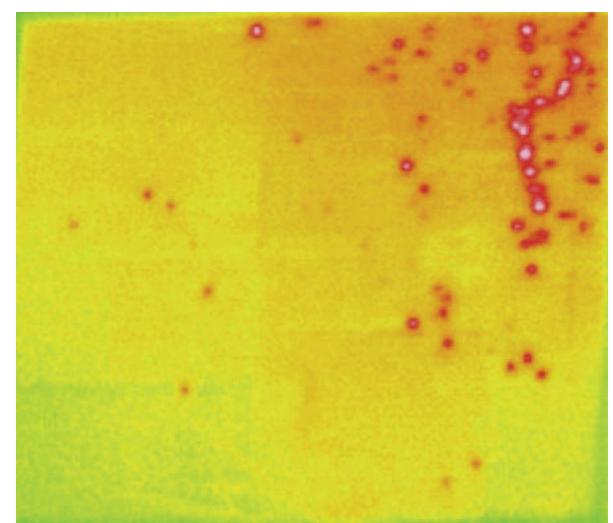

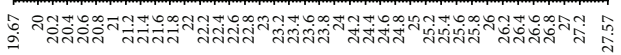

$\left({ }^{\circ} \mathrm{C}\right)$

FIGURE 5: Dark IR-image, a-Si-module (after aging). 
TABLE 1: Current-voltage measurement results.

\begin{tabular}{lccccc}
\hline & $U_{\mathrm{oc}}[\mathrm{V}]$ & $I_{\mathrm{sc}}[\mathrm{A}]$ & $U_{\mathrm{mp}}[\mathrm{V}]$ & $I_{\mathrm{mp}}[\mathrm{A}]$ & $P_{m}[\mathrm{~W}]$ \\
\hline Before aging & 23.59 & $\mathbf{7 . 0 7}$ & 16.97 & 5.73 & $\mathbf{9 7 . 2 3}$ \\
After aging & 22.98 & $\mathbf{5 . 1 9}$ & 16.60 & 4.13 & $\mathbf{6 8 . 5 2}$ \\
\hline
\end{tabular}

$U_{\mathrm{oc}}=$ open circuit voltage, $I_{\mathrm{sc}}=$ short circuit current, $U_{\mathrm{mp}}=$ voltage at $P_{m}$, $I_{\mathrm{mp}}=$ current at $P_{m}$, and $P_{m}=$ maximum power point.

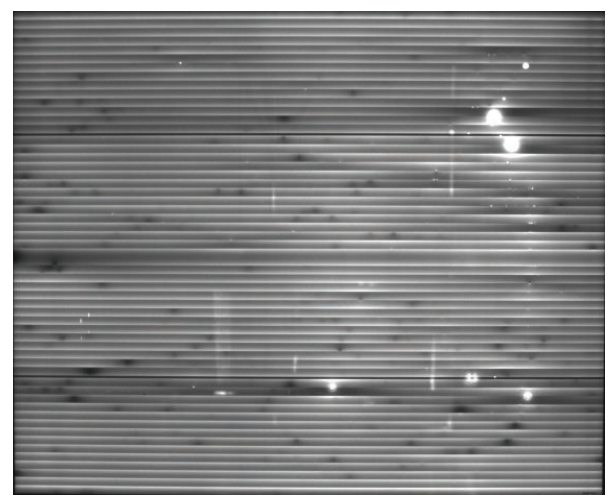

FIgURE 6: a-Si-module, EL-image.

EL-image. However, it is not always possible to identify the exact position of the defects.

As not all defects have an influence on the power output of cells or modules, performance measurements were executed in addition to the EL and IR measurements. These measurements show a relation between the increase of defects in a cell or module and the measured power losses.

After damaging the a-Si-module (Figure 4) a degradation of power of approximately $30 \%$ could be determined (Table 1). The reduced cell area leads to this power loss, mainly caused by the reduction of the short circuit current. The results of the current-voltage measurements before and after aging can be seen in Table 1 .

3.1.2. Characterization of an a-Si-Module under External Bias and under Illumination. Another a-Si-module was characterized by means of EL and IR measurements. Before EL and IR measurements only preconditioning via light soaking was performed. The IR measurements were performed under external bias and under illumination.

The EL-image of an a-Si-module (see Figure 6) mainly shows punctual shunts inside a cell or between the metal layers of two adjacent cells. Inside a cell the punctual shunts appear as black points and between two cells, where the current flows through the shunt to the Si-layer of the next cell, bright points appear in the EL-image by increased recombination of electron-hole pairs [10].

The thermography images of the a-Si-module (Figures 710) almost show the same defects compared to the EL-image (Figure 6). Only in Figure 8, analyzing the illuminated thermography image of the a-Si-module operated at maximum power point, it was not possible to identify the exact position of the defects. The metal junction box of this a-Si-module is clearly viewable as cooler area in all illuminated IR-image.

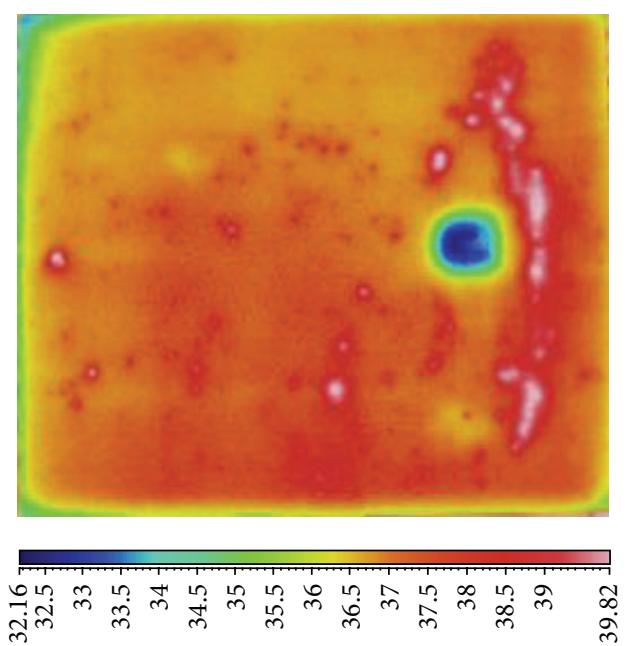

$\left({ }^{\circ} \mathrm{C}\right)$

Figure 7: a-Si, $I_{\text {sc }}$ operated, illuminated IR-image.

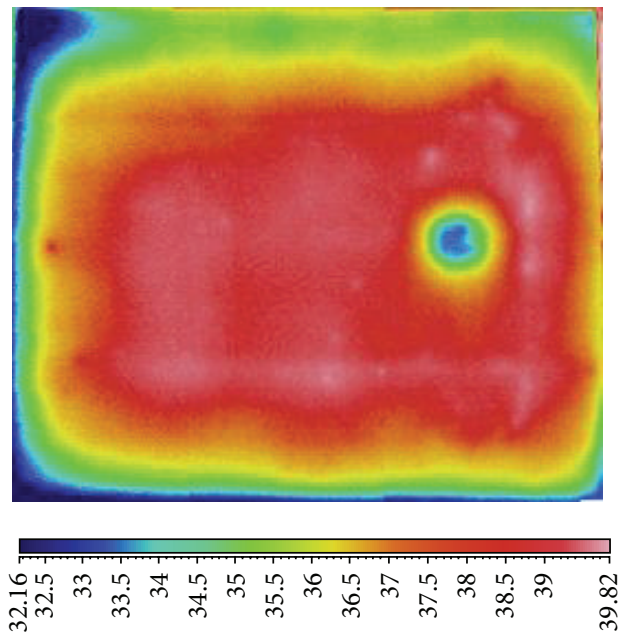

$\left({ }^{\circ} \mathrm{C}\right)$

FIGURE 8: a-Si, MPP operated, illuminated IR-image.

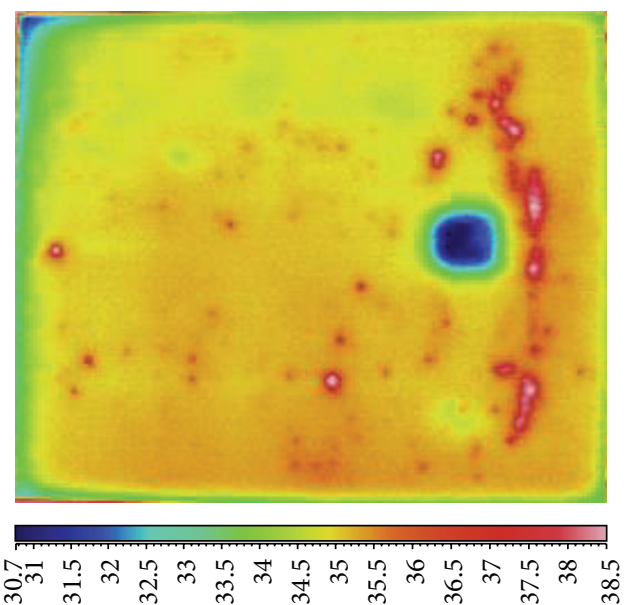

$\left({ }^{\circ} \mathrm{C}\right)$

Figure 9: a-Si, $U_{\text {oc }}$ operated, illuminated IR-image. 


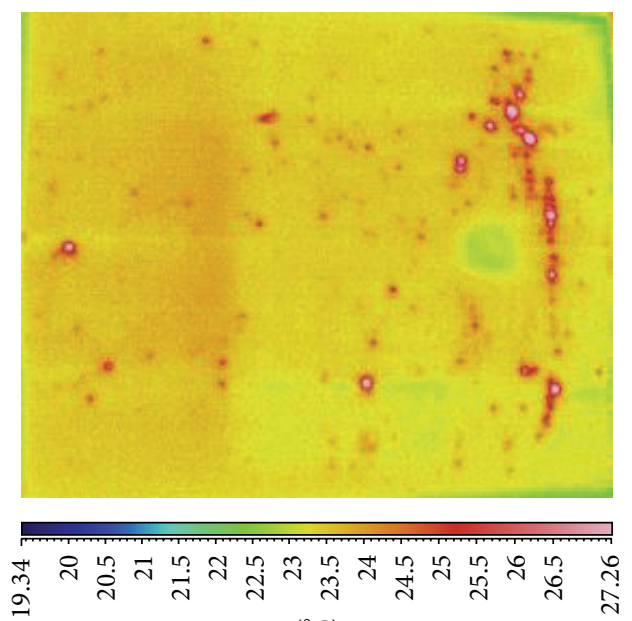

$\left({ }^{\circ} \mathrm{C}\right)$

FIGURE 10: a-Si, dark thermography image.

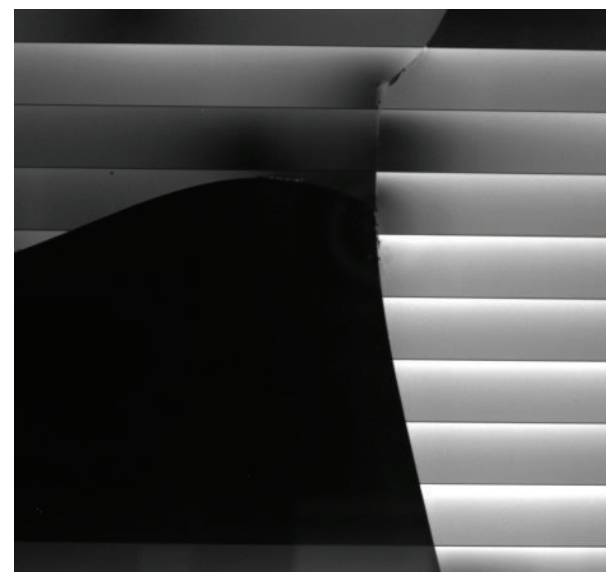

FIGURE 11: a-Si-module, EL-image.

Compared to the illuminated thermography images, the dark thermography image of the a-Si-module (Figure 10) supplies more details and a better defect resolution.

\subsubsection{Comparison of Electroluminescence and Photolumines-} cence Images of a Broken a-Si-Module. Figure 11 shows the EL and Figure 12 the PL-image of a third a-Si-module. The module was broken after transport. The PL-image clearly gives more information about the material properties and the position and the origin of the defect. It is thus a fast and contactless method to investigate defect thin film modules.

\subsection{Characterization of CdTe-Modules}

3.2.1. Injection Current-Dependent EL Measurements of a CdTe-Module. A new CdTe-module was characterized by means of EL and IR measurements. Before EL and IR measurements only preconditioning via light soaking was performed. To determine the influence of defects (e.g., shunts) the EL-behavior of the module when applying different current densities was investigated. When applying a low current

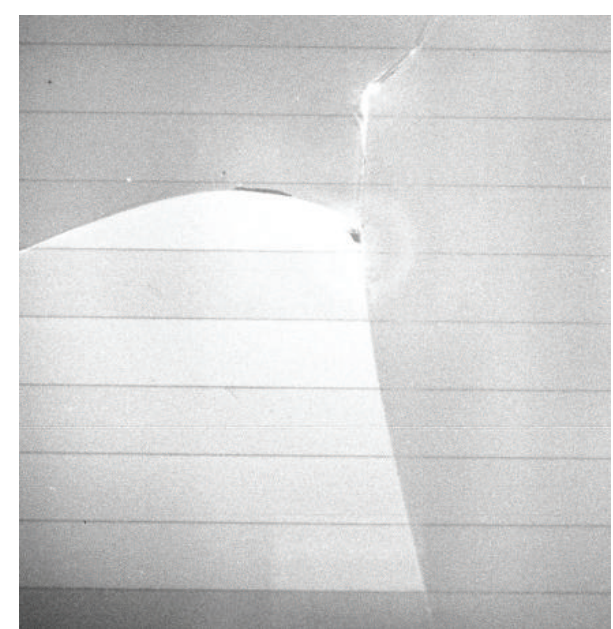

FIGURE 12: a-Si-module, PL-image.

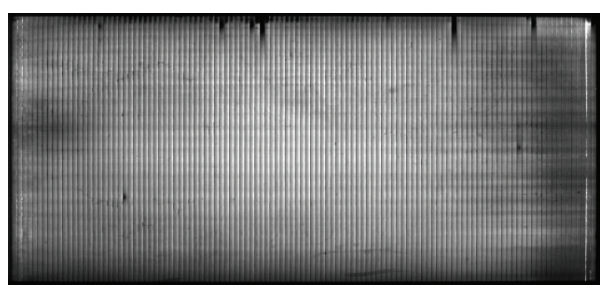

FIGURE 13: EL-image, CdTe-module (injected current: 1A).

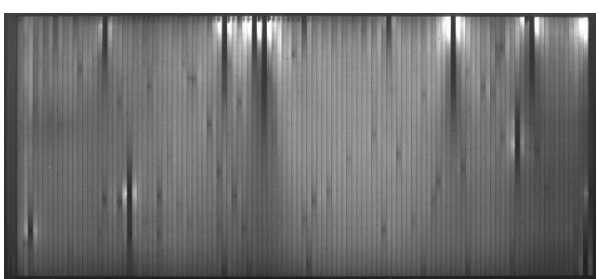

Figure 14: EL-image, CdTe-module (injected current: 0.1 A).

density the conductivity of shunts is very high. The stronger the shunts are the lower the EL intensity is in this area. Strong shunts are able to quench the EL intensity of a whole cell. When applying higher current densities, the conductivity of the pn-junction increases compared to the shunt conductivity, and shunts are less influential on the EL intensity distribution [21].

The EL-images of the CdTe-module, taken after applying different forward bias voltages, were compared. Figure 13 shows the EL-image of the CdTe-module with an injected current of $1 \mathrm{~A}$ ( $I_{\mathrm{sc}}$ of the module) and Figure 14 shows the ELimage with an injected current of $0.1 \mathrm{~A}$.

The comparison of the two EL-images shows very clearly that effective shunts are visible as punctual defects and thus better detectable when high currents are injected. On the contrary the EL intensity of the area around effective shunts is considerably increased when low currents are injected.

Most identified defects (mainly shunts) in the EL-image (Figure 14) of the CdTe-module are also visible in the dark 


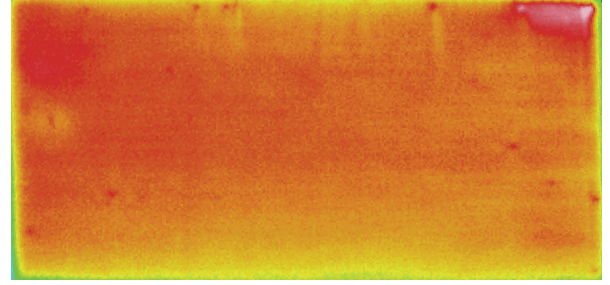

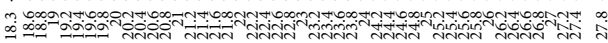

$\left({ }^{\circ} \mathrm{C}\right)$

FIGURE 15: Dark IR-image, CdTe-module.

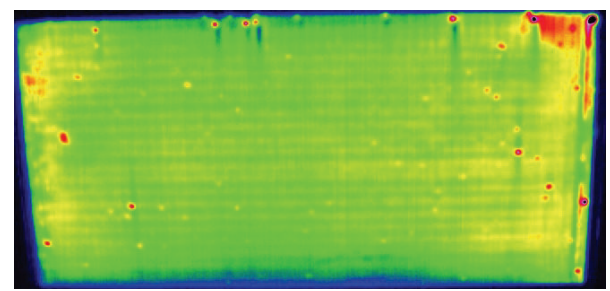

Figure 16: DLIT-image, CdTe-module. Temperature range: 0 to 0.05 Kelvin.

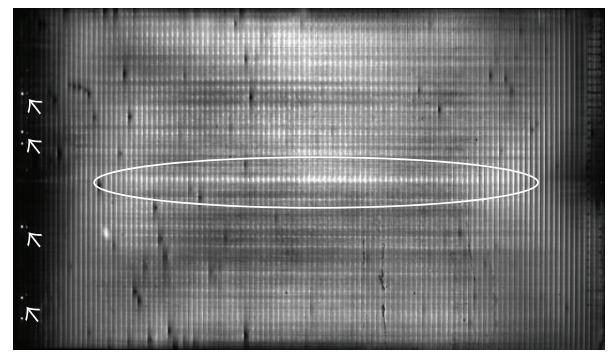

Figure 17: CdTe-module, EL-image.

thermography image (Figure 15). The hot spots identified in Figure 15 can be ascribed to areas with low shunt resistance, where the current flows through the defect and creates a heat source.

Figure 16 shows the dark lock-in thermography image (amplitude image) of the CdTe-module. Compared to the dark IR-image (Figure 15), the DLIT-image of the CdTemodule is even more detailed. The identification of the defect position is further improved and the DLIT-image is even better comparable to the EL-image (Figure 13). The interpretation is the same.

3.2.2. Characterization of a CdTe-Module under External Bias and under Illumination. A second CdTe-module was investigated. EL and IR measurements were performed. Before EL and IR measurements only preconditioning via light soaking was performed. Some identified defects (mainly shunts) in the EL-image (Figure 17) of the CdTe-module are also clearly visible in the dark thermography image (Figure 21). In the middle of the EL-image (marked with a white oval) there is an area with a very high intensity resulting from a higher local current density. This higher current density leads to an

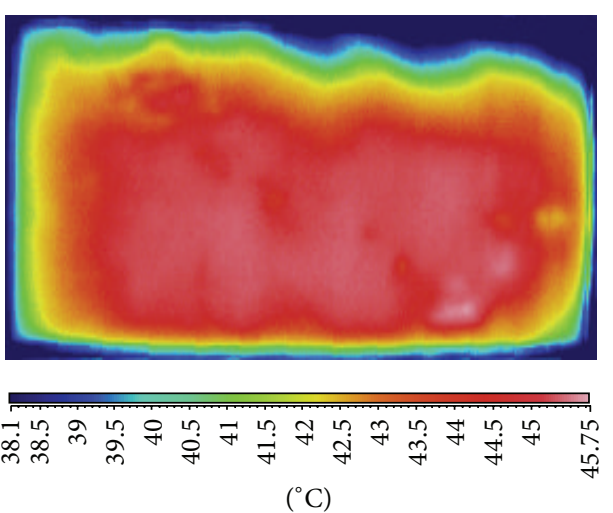

FIgURE 18: CdTe, $I_{\text {sc }}$ operated, illuminated IR-image.

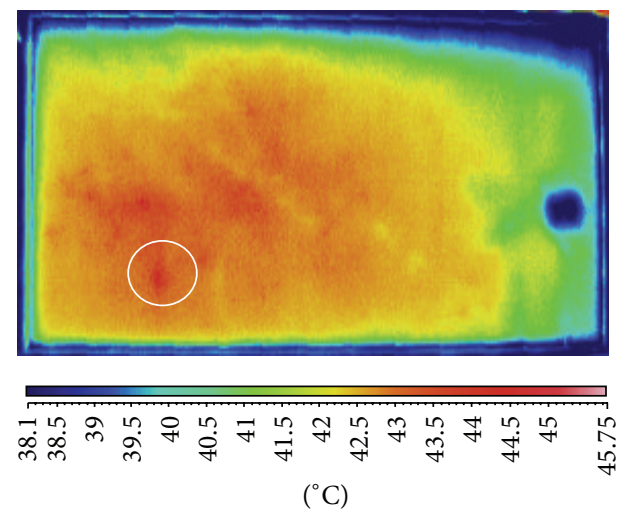

FIGURE 19: CdTe, MPP operated, illuminated IR-image.
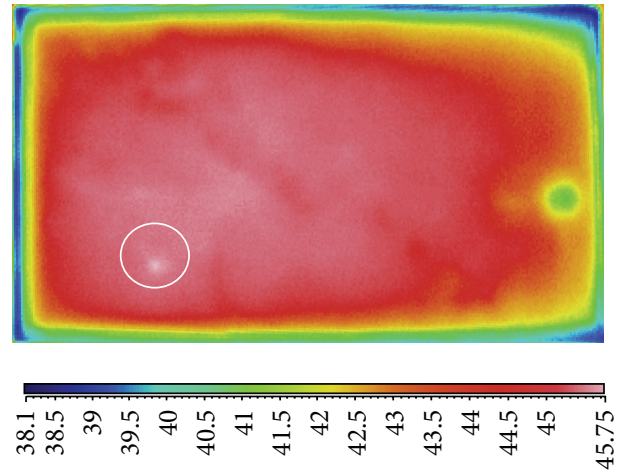

$\left({ }^{\circ} \mathrm{C}\right)$

Figure 20: CdTe, $U_{\text {oc }}$ operated, illuminated IR-image.

increased heat development which can also be seen in the dark thermography image (Figure 21) of the CdTe-module. A reason for this defect could be a decreased electrical contact area (caused by corrosion or aging) next to this very active area.

One shunt which is marked with a white circle in Figure 19 could also be identified in Figure 20. In Figure 19, the illuminated thermography image of the CdTe-module operated at $P_{m}$, more defects could be detected than in Figures 18 and 20. 

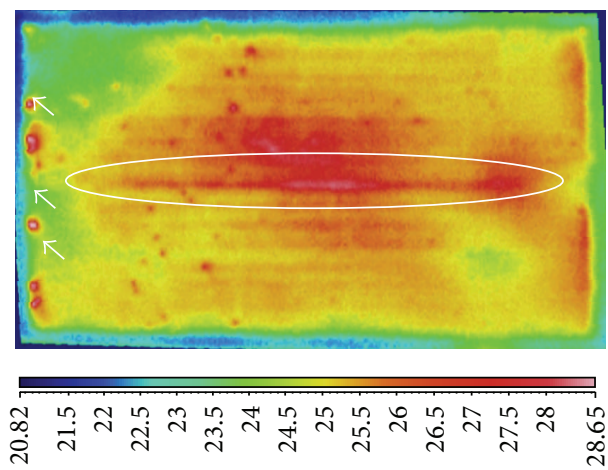

$\left({ }^{\circ} \mathrm{C}\right)$

Figure 21: CdTe, dark thermography image.

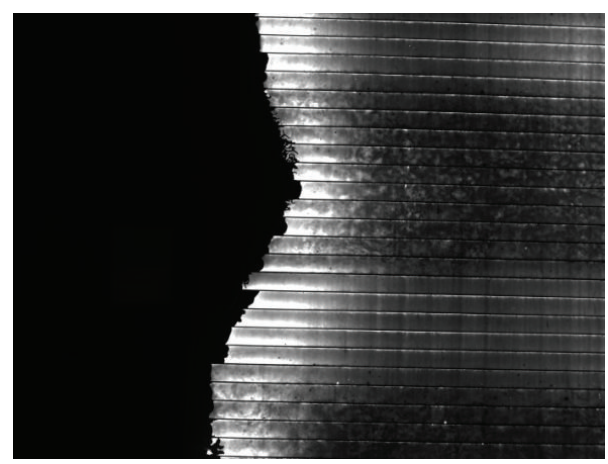

Figure 22: CdTe-module, EL-image.

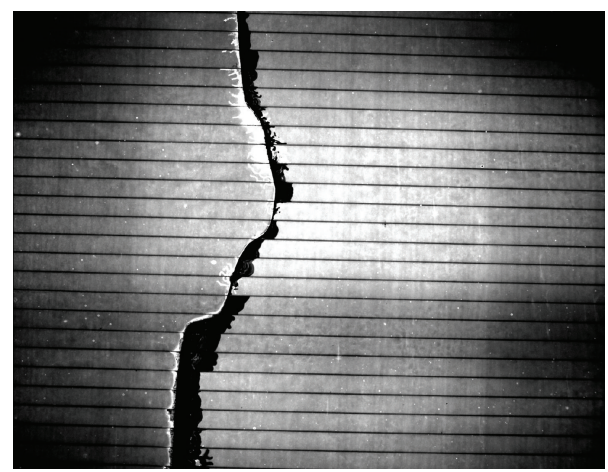

Figure 23: CdTe-module, PL-image.

Some shunts, which are not so clearly identifiable on the left side of the EL-image (Figure 17, marked with white arrows), are clearly visible in the dark thermography image (Figure 21).

These performed illuminated IR measurements of the CdTe-modules confirmed again that dark thermography is a better tool for defect detection than illuminated thermography.

\subsubsection{Comparison of Electroluminescence and Photolumines-} cence Images of a Broken CdTe-Module. Figure 22 shows the EL-image and Figure 23 the PL-image of a third CdTe-module. The module was broken after transport. The

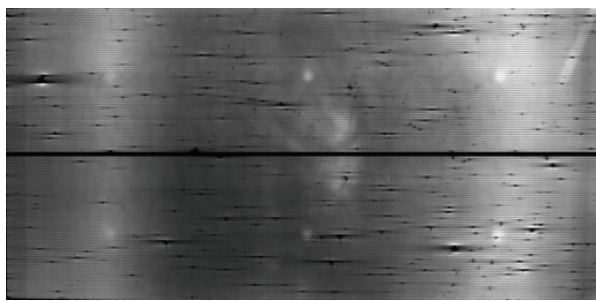

FIgURE 24: EL-image, CIS-module.

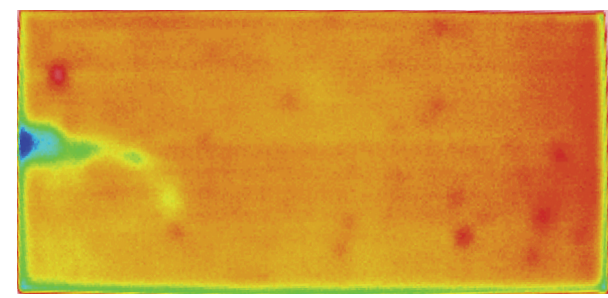

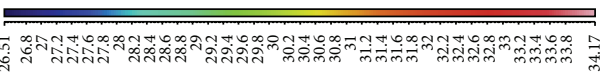

$\left({ }^{\circ} \mathrm{C}\right)$

FIGURE 25: IR-image, $I_{\text {sc }}$ operated, CIS-module.

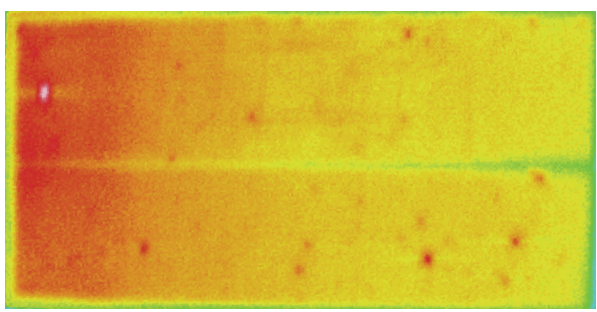

-

$\left({ }^{\circ} \mathrm{C}\right)$

FIgURE 26: Dark IR-image, CIS-module.

PL-image clearly gives more information about the material properties and the position of the defect.

\subsection{Characterization of CIS-Modules}

3.3.1. Comparison of Electroluminescence and Thermography Images of a CIS-Module. A new CIS-module is analyzed by EL and IR measurements [22]. Before EL and IR measurements only preconditioning via light soaking was performed. Figure 24 shows the EL-image of a CIS-module. Punctual areas of reduced EL intensity can be caused by shunts. As shunts are easier to locate at high current densities the $I_{\mathrm{sc}}$ of the module was applied.

By means of an illuminated thermography image (Figure 25) of the CIS-module operated under short circuit some hot spots are visible but not as clearly as in the dark thermography image (see Figure 26). 


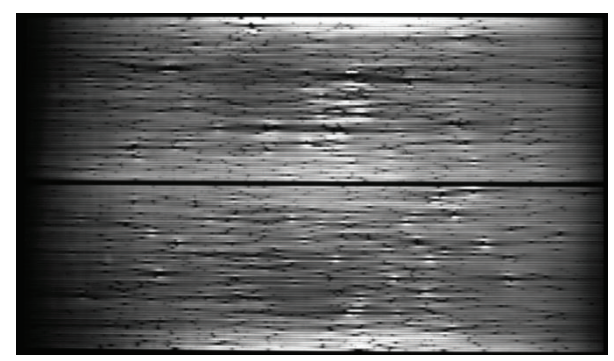

FIGURE 27: EL-image, CIS-module.

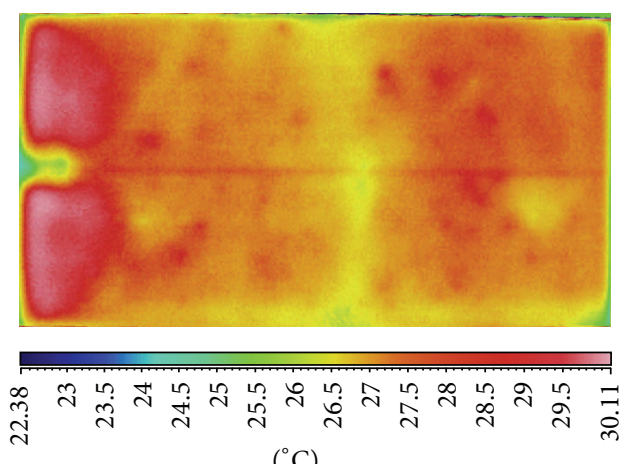

$\left({ }^{\circ} \mathrm{C}\right)$

FIGURE 28: CIS, $I_{\text {sc }}$ condition, illuminated IR-image.

It turned out that dark thermography measurements of CIS-modules generally supplied more detailed images than illuminated thermography measurements.

\subsubsection{Comparison of Electroluminescence and Thermography} of a Damaged CIS-Module. Figure 27 shows the EL-image of a CIS-module, where preconditioning via light soaking was performed and a reverse current $\left(<I_{\mathrm{sc}}\right)$ was applied. Punctual areas of reduced EL intensity are caused by shunts. Again the short circuit current $\left(I_{\mathrm{sc}}\right)$ of the module was applied in order to locate the shunts easier. The conductivity of the pnjunction increases with injected current densities compared to the shunt conductivity, and shunts are less influential on the EL intensity distribution.

The darker edges in the EL-image (see Figure 27) of the CIS-module, which corresponds well with a slight temperature rise in the IR-images, are due to reduced parallel resistance. In the case of reduced parallel resistance a part of the current flows through the shunt leaving less current to flow through the diode, which leads to a reduced EL intensity. The reason for reduced parallel resistance could be, for instance, conductive oxide layer corrosion.

By means of illuminated thermography images (Figures 28-30) and a dark thermography image of the CIS-module (Figure 31), a number of hot spots were identified. In Figures 28-30 hot spots can be ascribed to areas with low shunt resistance, where the current flows through the defect and creates a heat source.

The dark thermography image of this CIS-module again showed the defects (shunts) in more detail compared to the illuminated IR-images.

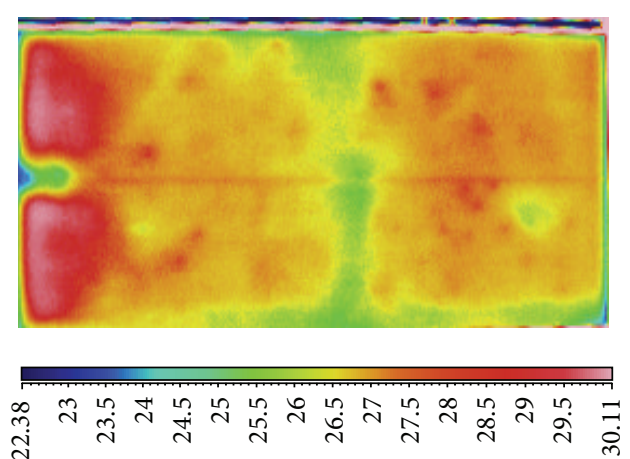

$\left({ }^{\circ} \mathrm{C}\right)$

FIGURE 29: CIS, MPP condition, illuminated IR-image.
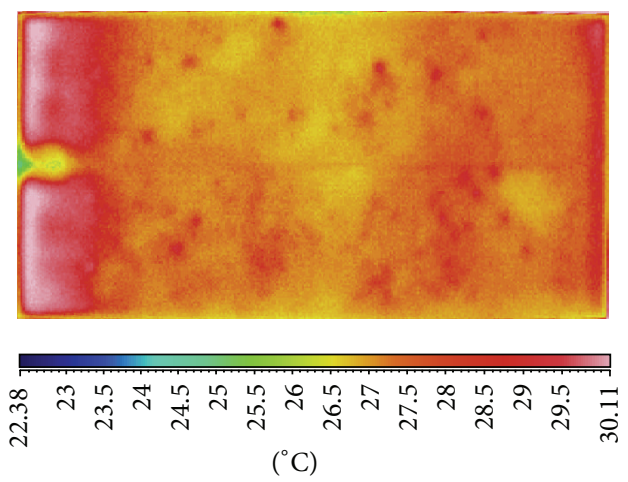

FIGURE 30: CIS, $U_{\text {oc }}$ condition, illuminated IR-image.
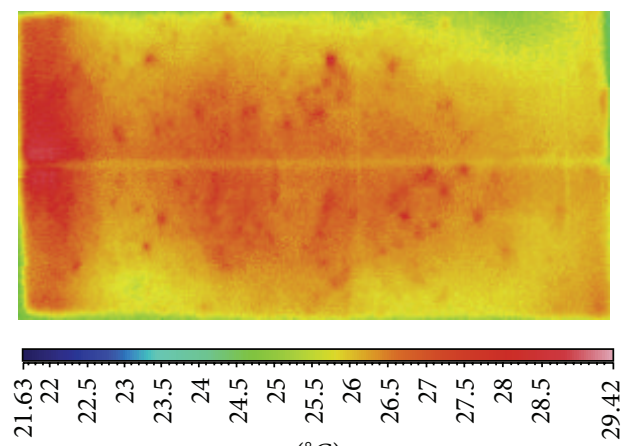

$\left({ }^{\circ} \mathrm{C}\right)$

FIGURE 31: CIS, dark thermography image.

Concerning IR-thermography measurements it could already be confirmed in previous publications that illuminated thermography is more suited for crystalline modules and dark thermography is a better tool for thin film modules [23]. Several defects can be distinguished by varying the electrical load corresponding to certain states on the currentvoltage characteristic. Under short circuit condition the IRimage gives an impression of different short circuits of single cells. If the module is illuminated and operated at maximum power point condition $\left(P_{m}\right)$, cells with low short circuit current $\left(I_{\mathrm{sc}}\right)$ no longer appear hot and only cells with high series resistance and severe cracks are identifiable. Modules 


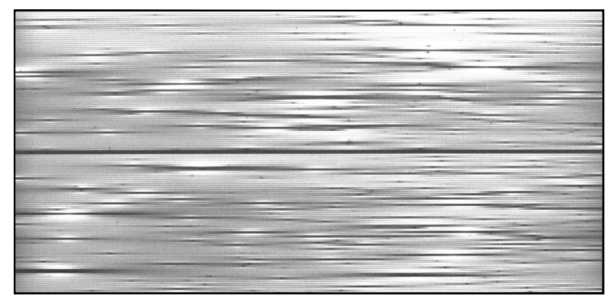

FIgURe 32: CIS-module, EL-image (0.1 A).

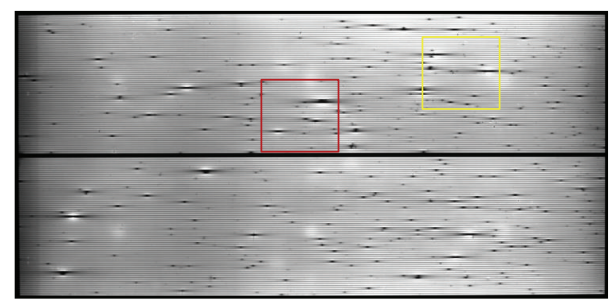

Figure 33: CIS-module, EL-image (1 A).

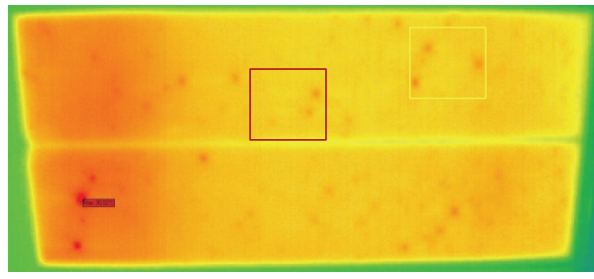

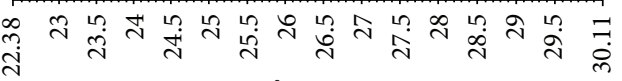

$\left({ }^{\circ} \mathrm{C}\right)$

FIGURE 34: CIS-module, dark IR-image.

operated under open circuit condition $\left(U_{\mathrm{oc}}\right)$ are expected to show heating mainly caused by low $I_{\mathrm{sc}}$ and not by increased series resistance [24].

In summary, it can be stated that dark thermography images, compared to illuminated thermography images, supply more details and a better defect resolution for thin film modules. For crystalline modules the opposite is true [2].

3.3.3. Comparison of EL-, IR-, and PL-Images of a CIS-Module. Another CIS-module was investigated by EL, IR, and PL measurements [25]. Before the measurements only preconditioning via light soaking was performed. The EL-images of a CIS-module, taken after applying different forward bias voltages, were compared (see Figures 32 and 33). In Figure 32 the effectiveness of the shunts could be identified and Figure 33 shows the position of the defects (mainly shunts) in more detail.

Figure 34 shows the dark IR-image of the CIS-module and Figure 35 the dark lock-in thermography image of the same module. In the DLIT-image the defects are given in more detail and are thus better comparable to failures discovered in the EL-image (Figure 33).

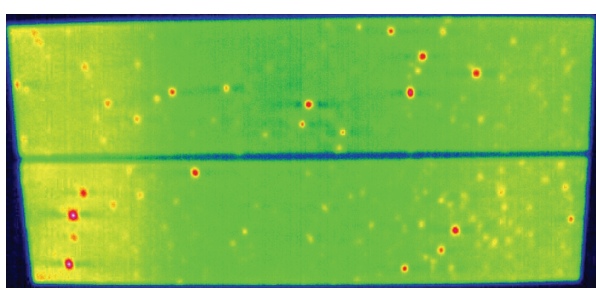

FIGURE 35: CIS-module, dark lock-in thermography image. Temperature range: $0-0.35$ Kelvin.

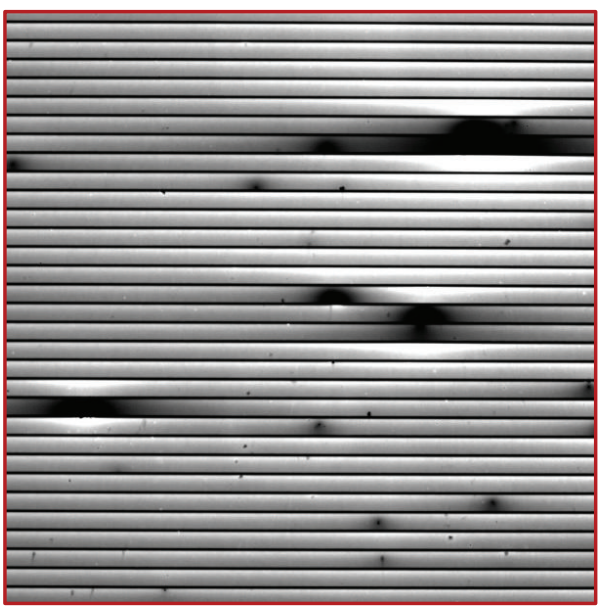

FIgURE 36: CIS-module, EL-image.

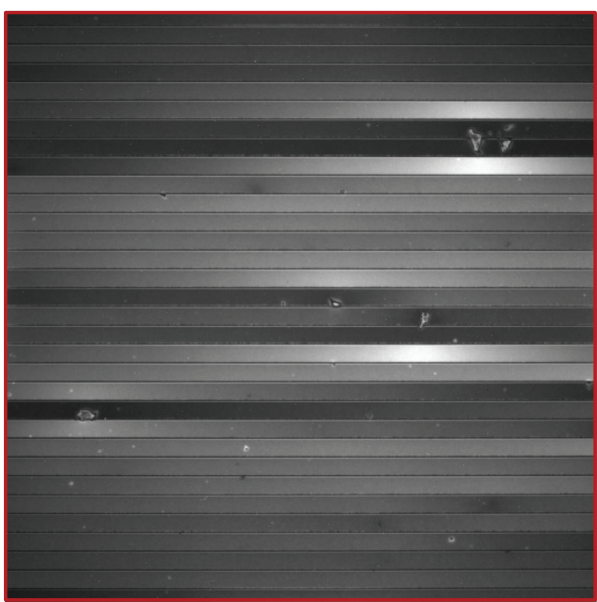

Figure 37: CIS-module, PL-image.

In addition photoluminescence (PL) measurements were executed in order to further increase the defect analysis (Figures 37 and 39). EL- and PL-images of two sections of the CIS-module, which were marked with a red and a yellow rectangle, were performed and compared. It can be clearly seen that the defects are given in more detail in the PL-images. In the EL-images there are only dark areas with no exact position of the defect (Figures 36 and 38). In the PL-image the exact position is determinable. 


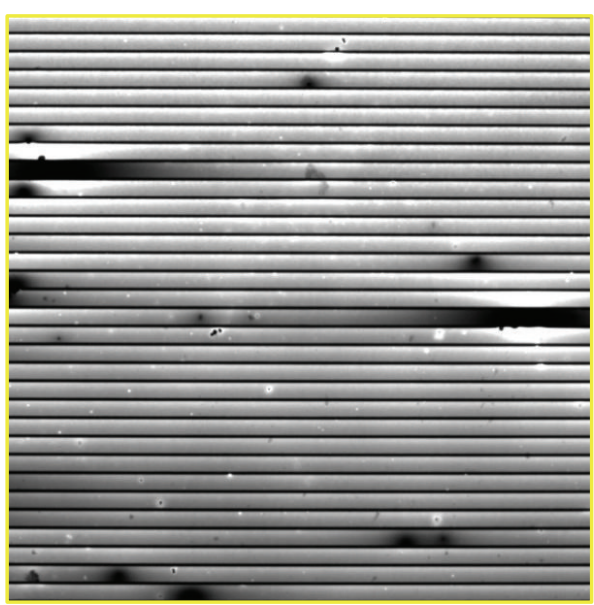

FIgure 38: CIS-module, EL-image.

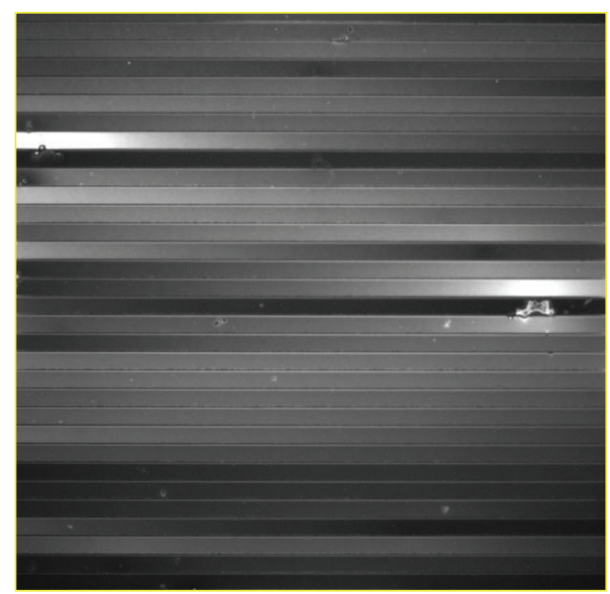

FIgURE 39: CIS-module, PL-image.

\section{Summary}

Table 2 shows a summary of the advantages and disadvantages of the different characterization methods (EL, PL, IR, and DLIT).

\section{Conclusion}

EL is a good method to detect microcracks, interrupted contacts, or a number of process failures (e.g., shunts) but it was not possible to determine the influence of these defects on the cell/module power output.

Performed IR measurements proved that on the one hand not all identified defects lead to an increase in temperature and on the other hand cells/modules with unremarkable ELimages sometimes supply IR-images with hot areas, which are caused by high power losses. In the thermography images of thin film modules the exact position of the defects could not always be identified and the great number of small spots made a determination difficult.

In the case of sun illuminated thermography, varying of the electrical load helps to distinguish several defects. If the voltage is increased from zero to voltage at $P_{m}$, some hot spots disappear because of the different $I_{\mathrm{sc}}$ of the cells. The hot spots which vanish if the voltage is increased towards $U_{\text {oc }}$ are caused by areas of increased series resistance [26].

DLIT-imaging is, compared to the dark IR imaging method, an improved characterization tool. The defects are better identifiable with a better resolution compared to dark IR measurements. Therefore, DLIT-images are also better comparable to failures discovered in the EL-image.

A very essential loss mechanism mainly for thin film modules is the loss due to localized shunts in the module. A typical thin film module consists of a number of elongated cells connected in series and separated from each other by scribe-lines. Shunt paths can be caused by imperfection in the scribing procedure, during film growth procedure (e.g., penetration of the junction depletion layer) or when layers are too thin or not properly deposited. The existence of localized shunts and, respectively, hot spots could also be proved in this work by means of EL and IR-thermography measurements.

Finally it could be proved that the effectiveness of defects (e.g., very strong shunts) is identifiable by means of currentdependent EL measurements.

First performed PL measurements of a-Si-, CdTe-, and CIS-modules were presented and compared with EL-images and IR-images. The PL-setup is further optimized.

PL measurements can be used to detect defects throughout the entire solar cell manufacturing process. In a previous work PL imaging was used for analyzing solar cells in PV modules and for the investigation of contact properties $[27,28]$. PL-images help to find out if material defects or contacting problems are the reason for power losses in solar cells and modules. Compared to EL-images, PL imaging has the advantage that contacting failures do not influence the contrast of the PL-images.

Concerning thin film modules (CIS), the investigation with PL helped to identify the origin of many defects. This could be a great advantage for module producers.

Furthermore, it could be demonstrated that PL imaging of solar cells and modules could be carried out successfully by means of LED excitation instead of hazardous and costly laser excitation. Thus, PL imaging could become a more interesting tool for the PV industry than EL imaging.

As the origin of a defect is not always located in the identified high temperature area or the remarkable dark ELareas, a combination of EL, PL, and IR techniques is necessary in order to identify as many defects as possible [29].

\section{Disclosure}

A poster about this topic was published at the 5th Photovoltaic Technical Conference-Thin Film \& Advanced Silicon Solutions, Centre de Congrès, Aix en Provence, May 2014. 
TABLE 2: Comparison of characterization methods.

$\oplus$

Electroluminescence (EL)

(i) High resolution

(ii) Identifiable

(a) Faulty laser scribing

(b) Process failures (e.g., shunts, layer defects, and TCO corrosion) (i) Origin of a defect is not identifiable

(ii) Difficult to determine influence of defects on cell/module performance

(iii) Unremarkable EL-images sometimes supply IR-images with hot areas

(iv) Electrical contact necessary

Photoluminescence (PL)

(i) Contactless

(ii) Identifiable

(a) Material properties (e.g., reduced minority carrier diffusion length)

(b) Process failures

(i) Contactless (illuminated)

(ii) Identifiable

(a) Different thermal behavior

(b) Shunts

(c) Hot spots

(d) Inactive cell parts

(e) Moisture

Dark lock-in thermography (DLIT)

(i) Identifiable

(a) Different thermal behavior

(b) Process failures (e.g., shunts)

(ii) Origin of a defect being identifiable (i) Homogenous illumination source necessary

(ii) Module measurements

Each cell separately

Infrared thermography (IR)

(i) Not contactless (dark)

(ii) Not all defects (EL) lead to a temperature increase

(iii) High temperature area: not always the origin of defects

(iv) Difficult to determine exact position of defects or large number of small spots

(v) Not distinguishable between low shunt and high series resistance

\section{Conflict of Interests}

The authors declare that there is no conflict of interests regarding the publication of this paper.

\section{References}

[1] S. Zamini, "Non-destructive-techniques for quality control of photovoltaic modules: electroluminescence imaging and infrared thermography," Photovoltaics International Journal, PV-Tech PRO, no. 15, pp. 127-203, 2012.

[2] R. Ebner, "Electroluminescence (EL) and infrared (IR) methods for characterizing different module technologies," in Proceedings of the 26th European Photovoltaic Solar Energy Conference and Exhibition, Hamburg, Germany, September 2011.

[3] R. Ebner, "EL an infrared IR methods for characterizing different thin-film module technologies," in Proceedings of the $3 \mathrm{rd}$ International Conference on Thin Film PV, Munich, Germany, 2011.

[4] C. Buerhop, "Quality control of PV-modules in the field using infrared-thermography," in Proceedings of the 26th European Photovoltaic Solar Energy Conference and Exhibition (EUPVSEC '11), Hamburg, Germany, 2011.

[5] U. Hoyer, C. Buerhop-Lutz, and U. Jahn, "Electroluminescence and infrared imaging for quality improvements of PV modules," in Proceedings of the 23rd European Photovoltaic Solar Energy Conference and Exhibition (EU-PVSEC '08), Valencia, Spain, September 2008.

[6] U. Hoyer, C. Buerhop-Lutz, and U. Jahn, "Electroluminescence and infrared imaging for quality improvements of PV modules," in Proceedings of the 23rd European Photovoltaic Solar Energy Conference and Exhibition (EU-PVSEC '08), pp. 2913-2916, Valencia, Spain, September 2008.

[7] U. Hoyer, A. Burkert, R. Auer et al., "Analysis of PV modules by electroluminescence and IR thermography," in Proceedings of the 24th European Photovoltaic Solar Energy Conference (EUPVSEC '09), pp. 3262-3266, Hamburg, Germany, September 2009.

[8] O. Breitenstein, Lock-in Thermography: Basics and Use for Functional Diagnostics of Electronic Components, Springer, 2003.

[9] O. Breitenstein, "Lock-in thermography- basics and use for functional diagnostic of electronic module technologies," in Proceedings of the the PV World Conference \& Expo, Tampa, Fla, USA, 2011.

[10] M. Ankner, "Analyse von fehlerbildern an dünnschichtmodulen über das EL-verfahren," in Proceedings of the 25th PV Symposium, Bad Staffelstein, Germany, March 2010.

[11] S. Roy, "Estimation of shunt resistance by electroluminescence imaging," in Proceedings of the 29th European Photovoltaic Solar Energy Conference and Exhibition, Amsterdam, The Netherlands, September 2014

[12] G. Wang, H. Gong, and J. Zhu, "Failure analysis of dark cells detected by electroluminescence (EL)," in Proceedings of the 28th European Photovoltaic Solar Energy Conference and Exhibition (EU-PVSEC '14), pp. 3173-3179, Amsterdam, The Netherlands, 2014.

[13] M. Köntges, M. Siebert, D. Hinken, U. Eitner, K. Bothe, and T. Potthof, "Quantitative analysis of PV-modules by electroluminescence images for quality control," in Proceedings of 
the 24th European Photovoltaic Solar Energy Conference (EUPVSEC '09), Hamburg, Germany, September 2009.

[14] T. Weber, "Electroluminescence investigation on thin film modules," in Proceedings of the 26th European Photovoltaic Solar Energy Conference and Exhibition (EU-PVSEC '11), Hamburg, Germany, 2011.

[15] A. Mansouri, "Defect detection in photovoltaic modules using electroluminescence imaging," in Proceedings of the Photovoltaic International, 2010.

[16] J. L. Crozier, "Identifying voltage dependant features in photovoltaic modules using electroluminescence imaging," in Proceedings of the 29th European Photovoltaic Solar Energy Conference and Exhibition (EU-PVSEC '14), Amsterdam, The Netherlands, 2014.

[17] T. Trupke, "Fast photoluminescence imaging of silicon wafers," in Proceedings of the IEEE 4th World Conference on Photovoltaic Energy Conversion, vol. 1, pp. 928-931, Waikoloa, Hawaii, May 2006.

[18] A. Lawerenz, "Photoluminescence lifetime using LED arrays exitation source," in Proceedings of the 25th European Photovoltaic Solar Energy Conference and Exhibition (PVSEC '10), Valencia, Spain, 2010.

[19] M. Bailly, "Photoluminescence lifetime characterization with low pressure sodium lamps," in Proceedings of the 28th European Photovoltaic Solar Energy Conference and Exhibition (EUPVSEC '13), Paris, France, 2013.

[20] R. Ebner, "Defect analysis of different photovoltaic modules using electroluminescene (EL) and infrared (IR)-thermography," in Proceedings of the 25th European Photovoltaic Solar Energy Conference and Exhibition (EU-PVSEC '10), Valencia, Spain, 2010.

[21] A. Helbig, T. Kirchartz, R. Schäffler, J. H. Werner, and U. $\mathrm{Rau}$, "Electroluminescence analysis of $\mathrm{Cu}(\mathrm{In}, \mathrm{Ga}) \mathrm{Se}_{2}$ thin-film modules," in Proceedings of the 24th European Photovoltaic Solar Energy Conference (EU-PVSEC '09), pp. 2446-2449, Hamburg, Germany, September 2009.

[22] A. Helbig, T. Kirchartz, R. Schäffler, J. H. Werner, and U. $\mathrm{Rau}$, "Electroluminescence analysis of $\mathrm{Cu}(\mathrm{In}, \mathrm{Ga}) \mathrm{Se}_{2}$ thin film modules," in Proceedings of the 24th European Photovoltaic Solar Energy Conference (EU-PVSEC '09), pp. 2446-2449, Hamburg, Germany, 2009.

[23] R. Ebner, "Defect analysis in different photovoltaic modules using electroluminescene (EL) and infrared (IR)-thermography," in Proceedings of the 25th European Photovoltaic Solar Energy Conference and Exhibition (EU-PVSEC '10), Valencia, Spain, 2010.

[24] U. Hoyer, A. Burkert, R. Auer et al., "Analysis of PV modules by electroluminescence and IR thermography," in Proceedings of the 24th European Photovoltaic Solar Energy Conference (EUPVSEC '09), pp. 3262-3266, Hamburg, Germany, September 2009.

[25] S. Johnston, T. Unold, I. Repins et al., "Imaging characterization techniques applied to $\mathrm{Cu}(\mathrm{In}, \mathrm{Ga}) \mathrm{Se}_{2}$ solar cells," Journal of Vacuum Science \& Technology A, vol. 28, p. 665, 2010.

[26] R. Ebner, "Electroluminescence (EL) and infrared (IR) imaging of different module technologies," in Proceedings of the PV World Conference \& Expo, Tampa, Fla, USA, 2011.

[27] R. Ebner, B. Kubicek, and G. Ujvari, "Non-destructive techniques for quality control of PV modules: Infrared thermography, electro- and photoluminescence imaging," in Proceedings of the 39th Annual Conference of the IEEE Industrial Electronics
Society (IECON '13), pp. 8104-8109, Vienna, Austria, November 2013.

[28] T. Trupke, R. A. Bardos, M. D. Abbott, F. W. Chen, J. E. Cotter, and A. Lorenz, "Fast photoluminescence imaging of silicon wafers," in Proceedings of the IEEE 4th World Conference on Photovoltaic Energy Conversion (WCPEC '06), vol. 1, pp. 928931, May 2006.

[29] R. Ebner, S. Zamini, and G. Újvári, "Defect analysis in different photovoltaic modules using electroluminescence (EL) and infrared (IR)-thermography," in Proceedings of the 25th European Photovoltaic Solar Energy Conference and Exhibition (PVSEC '10), pp. 333-336, Valencia, Spain, September 2010. 

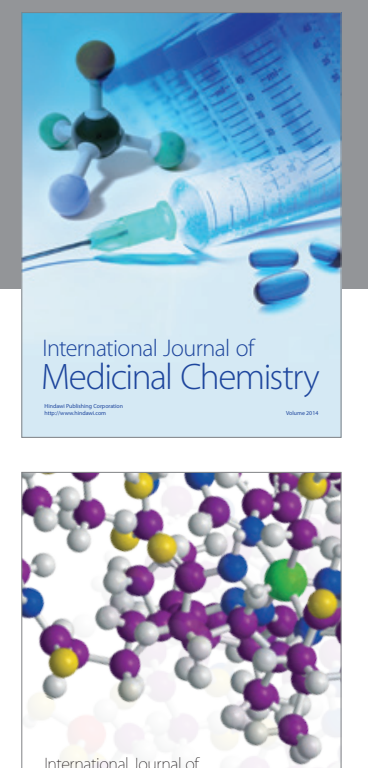

\section{Carbohydrate} Chemistry

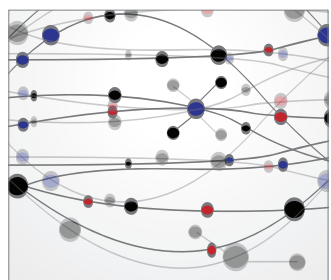

The Scientific World Journal
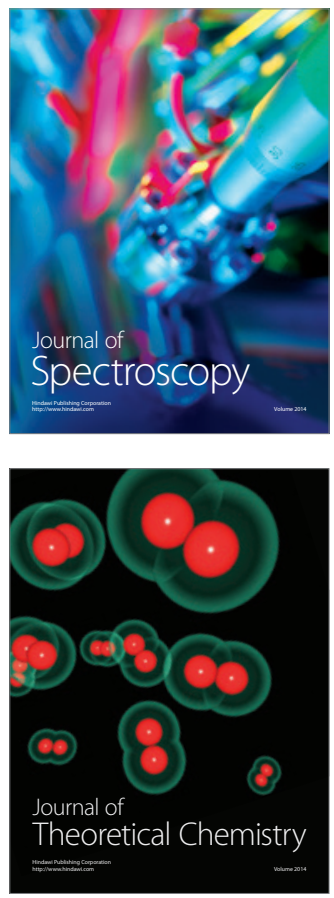
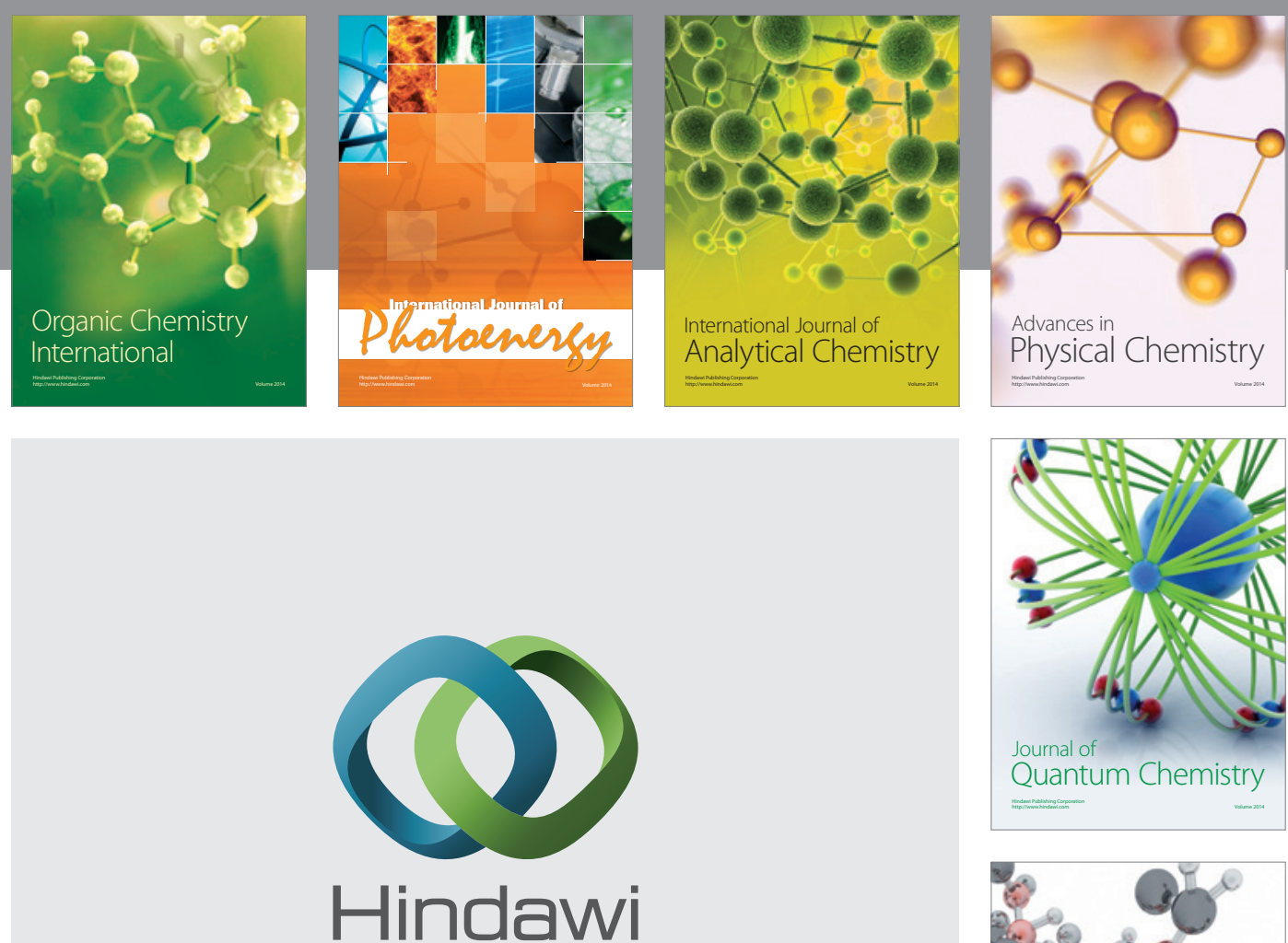

Submit your manuscripts at

http://www.hindawi.com

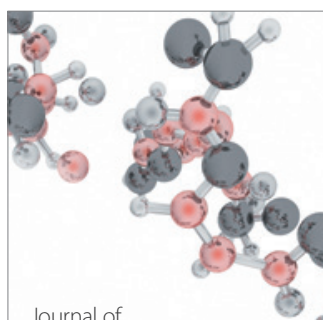

Analytical Methods

in Chemistry

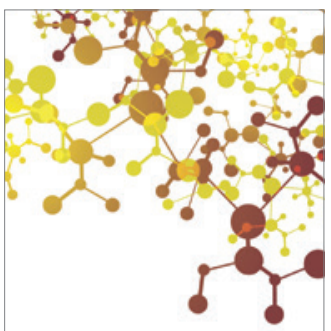

Journal of

Applied Chemistry

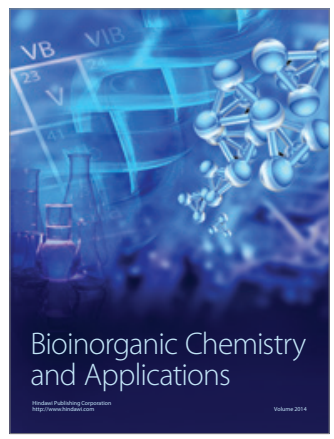

Inorganic Chemistry
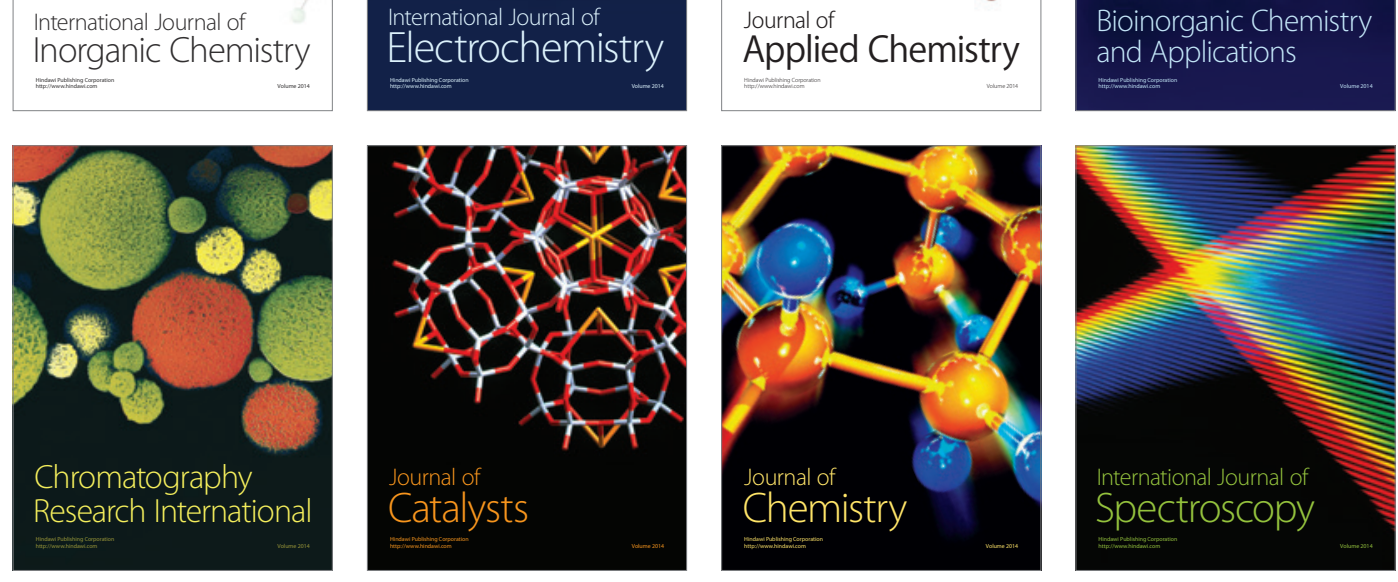